\title{
Divergência genética entre acessos de cenoura pertencentes a grupos varietais distintos utilizando caracteres morfológicos
}

\author{
Jairo Vidal Vieira'; Giovani Olegário da Silva ${ }^{1}$; Leonardo S Boiteux ${ }^{1}$; Philipp W Simon ${ }^{2}$ \\ ${ }^{1}$ Embrapa Hortaliças, C. Postal 218, $70359-970$ Brasília-DF; ${ }^{2}$ USDA-ARS, Vegetable Crops Research Unit, 1575 Linden Drive, \\ Department of Horticulture, University of Wisconsin, Madison, WI 53706 USA; olegario@cnph.embrapa.br
}

\begin{abstract}
RESUMO
A utilização de híbridos de cenoura tem aumentado consideravelmente na última década no Brasil. Estudos de determinação de divergência genética entre genótipos têm sido ferramentas de grande importância em programas de melhoramento, auxiliando na identificação de genitores com potencial heterótico. No entanto, pouco ainda se sabe sobre a capacidade combinatória de acessos de cenoura adaptados às regiões tropicais. Os objetivos do presente trabalho foram: (1) estimar parâmetros genéticos, (2) estimar a importância relativa de quatro caracteres morfológicos na discriminação de grupos varietais de cenoura e (3) obter indicação, a partir deste conjunto de dados morfológicos, de combinações promissoras para cruzamentos, visando utilização prática da heterose. Dois experimentos foram conduzidos em campo, nas primaveras de 2000 e 2001, no delineamento em blocos ao acaso com duas repetições. Foram avaliadas quinze plantas competitivas em cada parcela para os caracteres comprimento de folha, tamanho da raiz, diâmetro de raiz e massa fresca de raiz. Os dados foram submetidos às análises de variância, de dissimilaridade e da importância relativa dos caracteres. Todos os caracteres apresentaram valores de herdabilidade e da relação entre os coeficientes de variação genética e ambiental de medianos a altos. Os caracteres comprimento e diâmetro de raiz foram os que mais contribuíram para a diferenciação dos genótipos. O grupo mais divergente foi 'Imperator'. Desta forma, cruzamentos deste grupo com os demais acessos tendem a proporcionar maior efeito da heterose. Os acessos pertencentes ao grupo 'Brasília', podem ser cruzados com a maioria dos acessos (exceto para aqueles derivados dos grupos varietais 'Chantenay' e 'Danvers'), com probabilidade de geração de populações superiores em relação à heterose.
\end{abstract}

Palavras-chave: Daucus carota L., dissimilaridade, parâmetros genéticos.

\begin{abstract}
Genetic divergence among carrot accessions belonging to different varietal groups using morphologic characters

The utilization of carrot hybrids has increased in the last decade in Brazil. The estimative of genetic divergence among genotypes is a tool to identify superior parents for heterotic hybrid production in breeding programs. However, little is known about the combining ability of tropical-adapted carrot germplasm. The objectives of the present work were: (1) to estimate genetic parameters, (2) to estimate the relative importance of set of four morphological traits in the discrimination of carrot accessions belonging to distinct varietal groups and, (3) to use this morphological dataset combined with clustering techniques to group distinct carrot accessions in order to identify the most promising hybrid combinations. Two experiments were carried out in the field, in the springs of 2000 and 2001, in random block design with two replications. Fifteen competitive plants per accession were evaluated at 90 days after planting for the following traits: leaf length $(\mathrm{cm})$, root length $(\mathrm{cm})$, root diameter $(\mathrm{mm})$, and fresh root weight $(\mathrm{g})$. Analysis of variance as well as dissimilarity analysis and relative importance of each morphological characteristic for accession discrimination were calculated for the traits under study. All four traits displayed either medium or high heritability values as well as ratio of genetic and environmental variation coefficients. The traits root length and root diameter presented the highest contribution to discriminate accessions. The 'Imperator' group was the most divergent one. Therefore, crosses involving this variety group with the remaining accessions would result in progenies with the highest heterotic effects. Tropical-adapted accessions belonging to the 'Brasília' group could be crossed with the majority of the accessions (except for the ones corresponding to the 'Chantenay' and 'Danvers' groups) with a high probability of generating superior populations and/or heterotic gains.
\end{abstract}

Keywords: Daucus carota L., dissimilarity, genetic parameters.

\section{(Recebido para publicação em 8 de dezembro de 2008; aceito em 26 de setembro de 2009) (Received in December 8, 2008; accepted in September 26, 2009)}

\begin{abstract}
$\mathrm{N}$ o melhoramento genético de cenoura, que é uma planta alógama, estratégias envolvendo cruzamentos entre genótipos contrastantes possibilitam maximizar o efeito da heterose (Cruz \& Regazzi, 1997; Moura et al., 1999), sendo importante que os genitores apresentem em sua constituição genética
\end{abstract}

alelos superiores e sejam adaptados às condições locais de ambiente (Buzar et al., 2007).

O conhecimento dos componentes de variância é uma informação crucial dentro dos programas de melhoramento, permitindo estimar a herdabilidade, predizer o ganho genético dos caracteres, avaliar as potencialidades e limitações de uma dada população e a eficiência relativa dos diferentes métodos de melhoramento, auxiliando desta forma na identificação da estratégia de seleção mais adequada para cada característica de interesse (Dudley \& Moll, 1969; Hallauer \& Miranda Filho, 1981). Da 
mesma maneira, os estudos de divergência genética têm sido de grande importância em programas de melhoramento visando produção de híbridos gerando informações sobre parâmetros utilizados na identificação de genitores que possibilitem expressar maior efeito heterótico e aumentem a probabilidade de recuperar genótipos superiores nas progênies (Cruz \& Regazzi, 1997; Buzar et al., 2007; Paixão et al., 2008).

De acordo com Falconer (1981), a heterose e a capacidade específica de combinação entre dois genitores dependem da existência de dominância no controle do caráter e da presença de divergência entre os genitores.

A estimativa de divergência genética auxilia na identificação da variabilidade genética (Moura et al., 1999), informa a respeito das estratégias mais adequadas para organização do germoplasma, aumenta a eficiência da amostragem de genótipos, auxilia na definição de cruzamentos artificiais, na incorporação de genes de germoplasma exótico e até na recomendação de cultivares para determinada região, quando o objetivo é ampliar a base genética dos materiais utilizados nos cultivos comerciais (Mohammadi \& Prasanna, 2003). No entanto, esta estimativa é apenas um auxílio na predição e escolha dos cruzamentos mais promissores, pois há necessidade de que estes apresentem bom desempenho per se para as características mais importantes, que haja complementação gênica (Oliveira et al., 2000), boa capacidade de combinação, adaptação do genitor ao clima, etc. (Silva et al., 2007).

Neste contexto, os objetivos do presente trabalho foram: (1) estimar parâmetros genéticos (herdabilidade e relação entre coeficiente de variação genotípico e fenotípico) (2) estimar a importância relativa de quatro caracteres morfológicos na discriminação de grupos varietais de cenoura e (3) obter indicações, a partir destes dados morfológicos, das combinações híbridas mais promissoras para cruzamentos visando ganhos com a heterose, com ênfase nos grupos varietais de cenoura com adaptação aos trópicos e sub-trópicos.

MATERIAL E MÉTODOS
Foi avaliada uma coleção de 20 cultivares e 2 populações elite derivadas de diferentes continentes, grupos varietais e programas de melhoramento, pertencentes ao Banco Ativo de Germoplasma da Embrapa Hortaliças (Tabela 1).

Os experimentos foram conduzidos na Embrapa Hortaliças, Brasília-DF. Os acessos foram cultivados em condições de campo nas primaveras dos anos de 2000 e 2001, no delineamento em blocos ao acaso com duas repetições e parcelas de $2 \mathrm{~m}^{2}$ com espaçamento de $20 \mathrm{~cm}$ entre linhas e $5 \mathrm{~cm}$ entre plantas. Após desbaste, os tratos culturais limitaram-se a aplicação de herbicida pós-emergente e a retirada de plantas daninhas manualmente. A colheita foi efetuada aos 90 dias após o plantio para todas as cultivares. Foram colhidas e avaliadas 15 plantas competitivas dentro da área útil de cada parcela para os caracteres, comprimento de folha $(\mathrm{cm})$ com auxílio de régua, comprimento da raiz, com auxílio de régua $(\mathrm{cm})$, diâmetro de raiz ( $\mathrm{mm})$, com auxílio de paquímetro e massa de raiz (g), com auxílio de balança de precisão.

Os dados obtidos, após verificação das pressuposições pela análise homogeneidade de variância ("Bartllet's test for heterogeneity of error variances") e de normalidade ("Lilliefors's test statistic"), foram submetidos à análise de variância com informação entre e dentro de parcelas, conjunta e para cada ano de cultivo. Posteriormente, para cada ano, foi efetuada análise de dissimilaridade entre os genótipos pela divergência generalizada de Mahalanobis e da importância relativa dos caracteres, estimada por meio da participação dos componentes de $\mathrm{D}^{2}$, relativos a cada característica, no total da dissimilaridade observada (Singh, 1981) estas estimativas bem como os parâmetros genéticos herdabilidade e relação entre o coeficiente de variação genotípico e

Tabela 1. Acessos pertencentes ao Banco de Germoplasma da Embrapa Hortaliças e suas respectivas origens e tipos varietais (accessions of the Germplasm Bank of Embrapa Hortaliças and the respective origins and varietal types). Brasília, Embrapa Hortaliças, 2008.

\begin{tabular}{cllll}
\hline $\begin{array}{c}\text { Código dos } \\
\text { acessos }\end{array}$ & Nome & $\begin{array}{l}\text { Programa de } \\
\text { melhoramento }\end{array}$ & $\begin{array}{l}\text { País de } \\
\text { origem }\end{array}$ & Tipo varietal \\
\hline 1 & Kamila & Krzeszowice & Polônia & Nantes \\
2 & KCE897 & Krzeszowice & Polônia & Nantes \\
3 & Kalina & Krzeszowice & Polônia & Nantes \\
4 & Nabora & Krzeszowice & Polônia & Nantes \\
5 & Karotan & Bejo & Holanda & Flakkee \\
6 & Napoli & Bejo & Holanda & Nantes \\
7 & Nerac & Bejo & Holanda & Nantes \\
8 & Kazan & Bejo & Holanda & Flakkee \\
9 & Brasília & Embrapa & Brasil & Brasília \\
10 & Londrina & Londrina & Brasil & Brasília \\
11 & Prima & Agroflora & Brasil & Brasília \\
12 & Gold King & NK & EUA & Chantenay \\
13 & Nandrin & Bejo & Holanda & Nantes/Berlicum \\
14 & Blaze & Rogers & EUA & Imperator \\
15 & Commanche & SunSeeds & EUA & Imperator \\
16 & HCM & Crookham & EUA & High-Carotene \\
17 & Apache & SunSeeds & EUA & Imperator \\
18 & Danvers126 & NK & EUA & Danvers \\
19 & Primecut 59 & SunSeeds & EUA & Imperator \\
20 & Amsterdam Bak & Nunhems & Holanda & Amsterdam \\
21 & $(6366 * 2226)$ & $738-2$ & EUA & Imperator x Brasília \\
22 & $(6333 * 2226)$ & $738-3$ & EUA & Imperator x Brasília \\
\hline & & & &
\end{tabular}


fenotípico, foram realizados com utilização do programa GENES (Cruz, 2001). As matrizes de dissimilaridade foram transferidas para o programa NTSYSpc (Rohlf, 2000), para obtenção do agrupamento em dendrograma pelo método de agrupamento das divergências médias (UPGMA) e diagnóstico das correlações cofenéticas entre as matrizes e os agrupamentos (Rohlf \& Sokal, 1981), bem como as correlações entre as matrizes (Mantel, 1967).

\section{RESULTADOS E DISCUSSÃO}

Para todos os caracteres houve interação entre acessos e ano de cultivo. Desta forma, as análises de variância foram conduzidas separadamente para cada ano. De acordo com a Tabela 2, pode-se verificar que todos os valores obtidos para os caracteres em estudo foram significativos e capazes de diferenciar os acessos nos dois anos de avaliação. Os coeficientes de variação fenotípica apresentaram valores abaixo de $20 \%$, indicando boa precisão experimental, para todos os caracteres nos diferentes anos.

As relações entre os coeficientes de variação genética e o coeficiente de variação ambiental foram superiores para o ano de 2000, indicando que neste ensaio o ambiente influenciou menos na expressão dos caracteres em comparação com 2001. Todos os valores obtidos para todos os caracteres foram maiores que 1,0 em 2000, com destaque para comprimento de raízes $(3,56)$. Já para o ano de 2001, os caracteres tamanho de folha e comprimento de raiz tiveram predominância no coeficiente de variação de ordem ambiental, enquanto para diâmetro e massa fresca de raiz, a relação se manteve acima de 1,0, com maior valor para este último caráter $(1,80)$. Estes dados indicam a predominância de variação genética em relação à ambiental para estes caracteres, com maior confiabilidade dos valores fenotípicos observados uma vez que se referem, em grande parte, às características genotípicas (Tabela 2).

Quanto à herdabilidade, valores mais reduzidos foram observados para o ano de 2001 em comparação com 2002, com
Tabela 2. Resumo da análise de variância, herdabilidades, coeficientes de variação (CV) e contribuição relativa, em porcentagem, de cada caráter para a dissimilaridade de quatro caracteres fenotípicos avaliados em 22 acessos de cenoura (summarize of variance analysis, heritability, variation coefficients $(\mathrm{CV})$ and relative contribution, in percentage, of each character for the dissimilarity of phenotypic characters appraised in 22 carrot accessions). Brasília, Embrapa Hortaliças, 2008.

\begin{tabular}{|c|c|c|c|c|c|}
\hline \multirow[b]{2}{*}{ FV } & \multirow[b]{2}{*}{ Gl } & \multicolumn{4}{|c|}{ Quadrado médio de tratamento (Ano 2000) } \\
\hline & & $\begin{array}{c}\text { Tamanho } \\
\text { de folha }\end{array}$ & $\begin{array}{c}\text { Comprimento } \\
\text { de raiz }\end{array}$ & $\begin{array}{c}\text { Diâmetro } \\
\text { de raiz }\end{array}$ & $\begin{array}{c}\text { Massa de } \\
\text { raiz }\end{array}$ \\
\hline Acessos & 21 & $991,42 *$ & $359,67 *$ & $4,78^{*}$ & $7795,30 *$ \\
\hline Entre parcela & 21 & 115,11 & 20,59 & 0,58 & 1901,56 \\
\hline Dentro parcela & 616 & 18,59 & 7,23 & 0,13 & 473,75 \\
\hline $\mathrm{CV}(\%)$ & - & 9,01 & 6,94 & 8,17 & 19,00 \\
\hline $\mathrm{CVg} / \mathrm{CV}$ & - & 2,13 & 3,56 & 2,15 & 1,44 \\
\hline Herdabilidade & - & 0,88 & 0,94 & 0,87 & 0,75 \\
\hline \multirow[t]{3}{*}{ Contribuição relativa $^{1}$} & - & 7,88 & 70,46 & 21,04 & 0,62 \\
\hline & & \multicolumn{4}{|c|}{ Quadrado médio de tratamento (ano 2001) } \\
\hline & & $\begin{array}{c}\text { Tamanho } \\
\text { de folha }\end{array}$ & $\begin{array}{c}\text { Comprimento } \\
\text { de raiz }\end{array}$ & $\begin{array}{c}\text { Diâmetro } \\
\text { de raiz }\end{array}$ & $\begin{array}{c}\text { Massa de } \\
\text { raiz }\end{array}$ \\
\hline Acessos & 21 & $1846,50 *$ & $348,86^{*}$ & $955,85 *$ & $25937,59 *$ \\
\hline Entre parcelas & 21 & 806,05 & 129,21 & 173,70 & 4765,82 \\
\hline Dentro parcela & 616 & 35,02 & 11,63 & 22,79 & 1518,83 \\
\hline $\mathrm{CV}(\%)$ & - & 18,72 & 17,42 & 14,35 & 18,41 \\
\hline $\mathrm{CVg} / \mathrm{CV}$ & - & 0,82 & 0,97 & 1,61 & 1,80 \\
\hline Herdabilidade & - & 0,56 & 0,63 & 0,82 & 0,82 \\
\hline Contribuição relativa $^{1}$ & - & 8,13 & 25,45 & 47,98 & 18,43 \\
\hline
\end{tabular}

*Significativo a $5 \%$ de probabilidade de erro pelo teste $\mathrm{F}$ (significant at $5 \%$ of error probability for the F test).

${ }^{1}$ valor estimado de acordo com SINGH (1981) ( ${ }^{1}$ value estimated in accord with SINGH (1981)).

exceção para o caráter massa de raiz, que apresentou maior herdabilidade no segundo ano de cultivo $(0,82)$ e menor para o primeiro $(0,75)$. No entanto, foram observados valores para herdabilidade superiores a 0,80 nos dois anos de cultivo, exceto para massa fresca de raiz em $2000(0,75)$ e tamanho de folha e comprimento de raiz em $2001(0,56$ e 0,63 ), respectivamente (Tabela 2), confirmando que a variação de ordem genética predominou sobre a fenotípica para a maioria dos caracteres. Os valores de herdabilidade verificados no presente trabalho diferem dos resultados obtidos em outros estudos. Alves et al. (2006) encontraram valores de 0,42 e 0,29 para os caracteres comprimento e diâmetro de raiz, respectivamente. Por sua vez, McCollum (1971) considerou estes caracteres como tendo reduzidos valores para herdabilidade. Estas discrepâncias com os valores superiores estimados no presente trabalho podem ser explica- das pelo fato de cada trabalho ter sido conduzidos em um ambiente de cultivo diferente e com materiais genéticos também distintos.

Quanto à importância relativa dos caracteres estudados, considerando os dois anos de avaliação, verifica-se que comprimento e diâmetro de raiz foram os que mais contribuíram para a diferenciação dos genótipos (Tabela 2). Desta forma, o agrupamento dos acessos foi predominantemente influenciado por essas duas características.

A comparação entre as duas matrizes de divergência foi realizada através da correlação entre matrizes (Mantel, 1967). O valor de correlação entre estas foi de 0,87 sendo significativa pelo teste de Mantel (1967) e indicando que os genótipos foram agrupados de forma bastante semelhante nos dois anos de cultivo. Estes resultados indicaram que os genótipos expressaram suas caracte- 


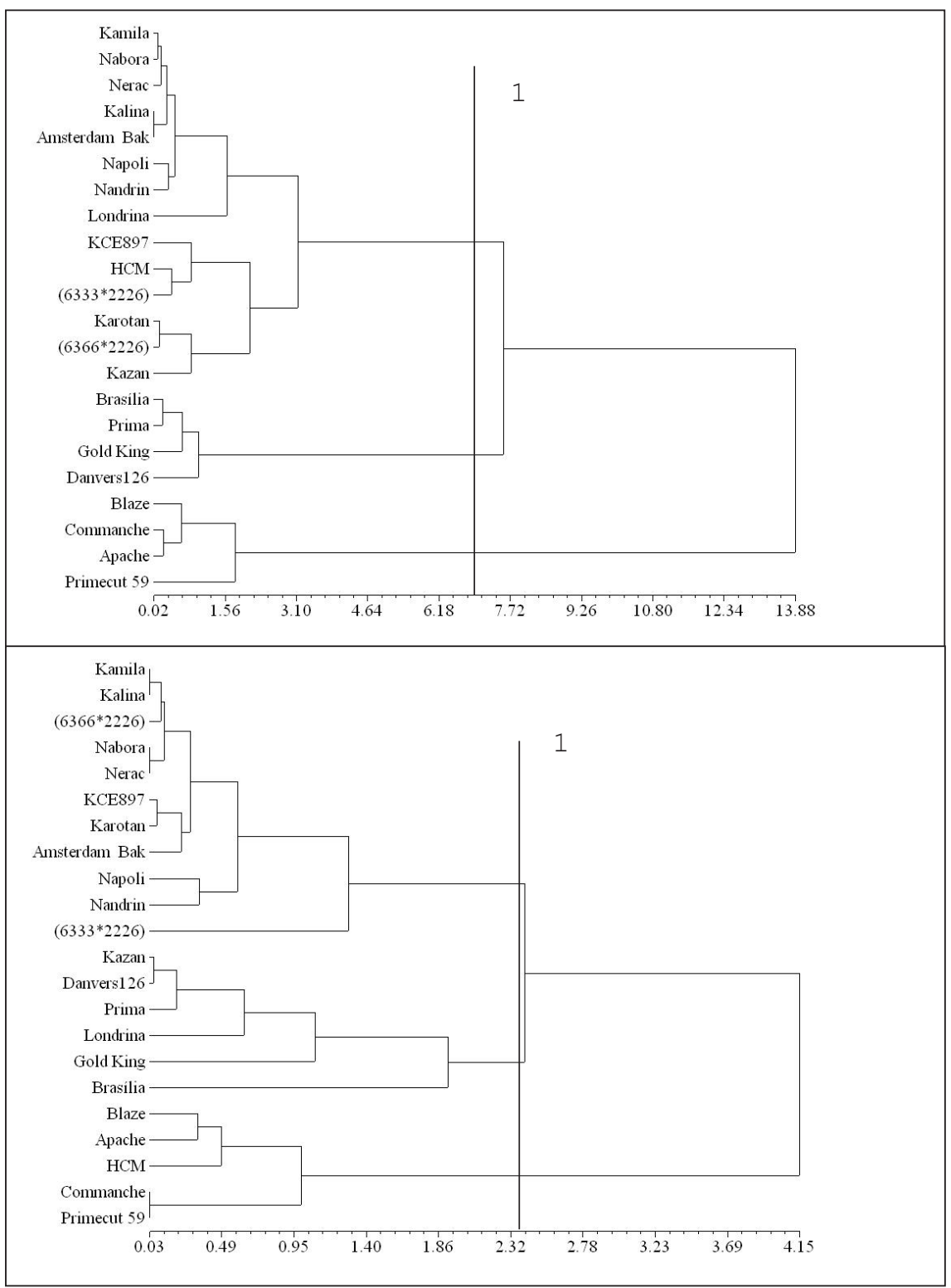

Figura 1. Dendrogramas de divergência entre 22 acessos de cenoura, com base em dados de quatro caracteres morfológicos, para o ano de 2000 e 2001, respectivamente, agrupados pelo método de agrupamento UPGMA. (Dendrograms of distance among 22 carrot accessions based on four morphologic data, for the year 2000 and 2001, respectively, group by the grouping method UPGMA.) ${ }^{1}$ Divergência média entre os genótipos (' ${ }^{1}$ average distance among genotypes). Brasília, Embrapa Hortaliças, 2008.

rísticas também de forma semelhante nestes dois anos.

Os dendrogramas representativos da divergência entre os genótipos para os dois anos, podem ser visualizados na Figura 1. Os coeficientes da correlação cofenética, que indicam quanto os dados das matrizes de dissimilaridade estão representados nos dendrogramas, foram de 0,76 e 0,71 , para os anos de 2000 e 2001, respectivamente, indicando que os dados das matrizes estão bem representados nos dendrogramas

\section{(Mantel, 1967).}

O dendrograma obtido para o primeiro ano de cultivo, de acordo com a divergência média entre os acessos $(7,04)$, indica haver um grupo maior composto por 14 dos 22 acessos avaliados, e dois agrupamentos menores compostos por quatro acessos cada um. Esta distribuição indica que a maioria dos acessos apresentou níveis de similaridade muito grandes e que, para maximizar a heterose, os componentes dentro de cada grupo não poderiam ser cruzados entre si (Luthra et al., 2005).

A dissimilaridade média entre os acessos para o segundo ano foi de 2,35, demonstrando que 11 deles ficaram agrupados num grupo maior e que dois outros grupos menores foram formados, um com seis e outro com cinco acessos, com um padrão de agrupamento muito similar aos do ano anterior. Estes resultados confirmam que os acessos tiveram desempenho semelhante para o conjunto de características avaliadas nos dois anos, indicando a consistência das conclusões acerca dos agrupamentos obtidos, apesar da presença de interação entre acessos e ano de cultivo.

Um dos dois grupos menores do primeiro ano foi formado por todos os acessos do tipo 'Imperator' ('Blaze', 'Commanche', 'Apache' e 'Primecut 59'). Da mesma forma estes foram separados em um mesmo grupo no segundo ano, com exceção do genótipo 'HCM' que se mostrou semelhante fenotipicamente ao grupo maior composto por vários acessos de origens distintas. Pode-se verificar que, em ambos os anos, o grupo 'Imperator' foi o mais divergente. Neste contexto, pode-se concluir que os cruzamentos entre acessos do grupo 'Imperator' com acessos dos demais grupos varietais tendem a proporcionar maior efeito de heterose.

De acordo com os caracteres estudados, para os dois anos, os acessos 'Brasília' e 'Prima' (ambos do grupo varietal 'Brasília') agruparam próximos a outros dois acessos ('Gold King' e 'Danvers 126'). Estes resultados indicam que ganhos expressivos com heterose não são esperados nos cruzamentos entre acessos do grupo 'Brasília' e aqueles representando os grupos varietais 'Chantenay' e 'Danvers'. O acesso 'Londrina' (também pertencente ao tipo 'Brasília') assemelhou mais aos acessos do tipo 'Nantes' (pertencentes ao agrupamento maior no primeiro ano). No segundo ano, o acesso 'Londrina' agrupou próximo ao acesso 'Kazan' (do grupo 'Flakkee') que também agrupou junto ao grupo varietal 'Brasília', diferentemente do primeiro ano, onde se assemelhou mais ao acesso 'Karotan' (tipo 'Flakkee').

Os seis acessos do tipo 'Nantes' e o acesso 'Nandrin' (tipo 'Nantes' $x$ 
'Berlicum'), que contém contribuição da tradicional cultivar 'Nantes' em sua genealogia, formaram um mesmo grupo nos dois anos. O acesso 'Amsterdam Bak' (único representante do grupo 'Amsterdam') agrupou nos dois anos próximo aos acessos do tipo varietal 'Nantes', indicando que seu cruzamento com genótipos do grupo varietal 'Nantes' não proporcionaria grande efeito heterótico nas progênies. Os acessos $(6333 * 2226)$ e $(6366 * 2226)$, derivados de cruzamento intervarietal 'Imperator $x$ Brasília', ficaram no grupo maior de acessos nos dois anos, não se assemelhando nem com os outros tipos 'Brasília' e nem com os acessos do tipo 'Imperator'.

O presente estudo indicou que todos os quatros caracteres apresentaram valores de herdabilidade e a relação entre os coeficientes de variação genética e ambiental medianos a altos; os caracteres comprimento e diâmetro de raiz foram os que mais contribuíram para a divergência genética; o grupo que mais se diferenciou dos demais pela análise de dissimilaridade foi o tipo 'Imperator', indicando que cruzamentos intervarietais envolvendo este grupo podem proporcionar maiores efeitos de heterose. Os acessos do grupo 'Brasília', não devem ser cruzados apenas com os acessos dos grupos varietais 'Chantenay' e 'Danvers'.

\section{REFERÊNCIAS}

ALVES JCS; PEIXOTO JR; VIEIRA JV; BOITEUX LS. 2006. Herdabilidade e correlações genotípicas entre caracteres de folhagem e sistema radicular em famílias de cenoura, cultivar Brasília. Horticultura Brasileira 24: 363-367.

BUZAR AGR; OLIVEIRA VR; BOITEUX LS. 2007. Estimativa da diversidade genética de germoplasma de cebola via descritores morfológicos, agronômicos e bioquímicos. Horticultura Brasileira 25: 513-518.

CRUZ CD; REGAZZI AJ. 1997. Divergência genética In: CRUZ CD; REGAZZI, AJ. Métodos Biométricos Aplicados ao Melhoramento Genético. Viçosa, UFV: Imprensa Universitária 6: 287-324.

CRUZ CD. 2001. Programa Genes: Aplicativo computacional em genética e estatística. Viçosa, Editora UFV 648p.

DUDLEY JW; MOLL RH. 1969. Interpretation and use of estimates of heritability and genetic variances in plant breeding. Crop Science 9: 257-262.

FALCONER DS. 1981. Introdução à Genética Quantitativa. Tradução de Silva MA e Silva JC. Viçosa-MG: UFV, Impr. Univ., 279p.

HALLAUER AR; MIRANDA FILHO JB. 1981. Quantitative Genetics in Maize Breeding. Ames, Iowa State University Press, 468 p.

LUTHRA SK; GOPAL J; SHARNA PC. 2005. Genetic divergence and its relationship with heterosis in potato. Indian Potato Journal 32: $37-42$.
MCCOLLUM GD. 1971. Greening of carrot roots (Daucus carota L.): Estimates of heritability and correlation. Euphytica 20: 549-560.

MANTEL N. 1967. The detection of disease clustering and a generalized regression approach. Cancer Research 27: 209-220.

MOHAMMADI SA; PRASANNA BM. 2003. Analyses of genetic diversity in crop plants - Salient statistics tools and considerations. Crop Science 43:1235-1248.

MOURA WM; CASALI VWD; CRUZ CD; LIMA PC. 1999. Divergência genética em linhagens de pimentão em relação à eficiência nutricional de fósforo. Pesquisa Agropecuária Brasileira 34: 217-224.

OLIVEIRA ACB; SEDIYAMA MAN; SEDIYAMA T; CRUZ CD. 2000. Avaliação da divergência genética em batata-doce por procedimentos multivariados. Acta Scientiarum 22: 895-900.

PAIXÃO SL; CAVALCANTE M; FERREIRA PV; MADALENA JAS; PEREIRA RG. 2008. Divergência genética e avaliação de populações de milho em diferentes ambientes no estado de alagoas. Caatinga 21: 191-195.

ROHLF FJ. 2000. NTSYSpc Numerical Taxonomy and Multivariate Analysis System Version 2.1. Exeter Software, Setauket, NY.

ROHLF FJ; SOKAL RRN. 1981. Comparing numerical taxonomic studies. Systematic Zoology 30: 459-499.

SILVA GO; PEREIRA AS; SOUZA VQ; CARVALHO FIF; NEY VG. 2007. Influência da distância entre genitores de batata nas estimativas de capacidades de combinação em gerações iniciais de seleção. Magistra 19: 177-264.

SINGH, D. 1981. The relative importance of characters affecting genetic divergence. The Indian Journal of Genetics and Plant Breeding 41: 237-245. 